\title{
Imagery Rescripting Helps Victims Cope With Experienced Injustice
}

\author{
Mathias Twardawski, Mario Gollwitzer, Marlene S. Altenmüller, Anna E. Kunze, \\ and Charlotte E. Wittekind
}

Department of Psychology, Ludwig-Maximilians-Universität München, Germany

\begin{abstract}
In clinical psychology, imagery rescripting (ImRs) is a promising intervention to target negative emotional memories after victimization experiences. The present research tested the effects of ImRs in "minor" cases of experienced injustice. After imagining being the victim of an injustice, participants ( $N=272$ ) were randomly assigned to one of four conditions in a univariate design (treatment: active ImRs, passive ImRs; control: pleasant imagery, imagery rehearsal). Dependent variables were positive and negative affect; mediator variables were justice-related satisfaction and empowerment. Both justice-related satisfaction and empowerment increased positive and decreased negative affect, but empowerment was higher in the active than in the passive ImRs condition (while justice-related satisfaction was increased by both ImRs conditions). These results suggest that ImRs can be beneficial even in minor victimization experiences and that these beneficial effects are mediated by both empowerment and justice-related satisfaction.
\end{abstract}

Keywords: imagery rescripting, punishment, injustice, empowerment, justice-related satisfaction

Victims of injustice often experience strong negative emotions - anger, anxiety, moral disgust, and so forth and these emotions often persist long after the incident has occurred. Particularly traumatic incidents can even have long-term effects on victims' well-being, sometimes requiring professional psychotherapeutic treatment. Notably, even "minor" everyday injustices can evoke unpleasant affective reactions such as angry rumination, "why-me" questions, and vengeful desires (Barber et al., 2005; Pedersen et al., 2011), some of which are even put into action (Hofmann et al., 2018). Retaliating against the transgressor is often emotionally ambivalent (Eadeh et al., 2017); yet, it can increase victims' feelings of empowerment (Strelan et al., 2017, 2020) and a sense of justice (Funk et al., 2014; Gollwitzer et al., 2011).

Sometimes, however, punishing the original harm-doer may neither be feasible nor wise, for example, when transgressors are of higher status. In these cases, people often indulge in vengeful fantasies (Goldner et al., 2019), anticipating this to be pleasurable. However, the extent to which retaliation fantasies extinguish versus feed the flame is currently unclear. In clinical research, such fantasies have been found to contribute to the maintenance of post-traumatic stress disorder (PTSD) symptoms in traumatized patients (Gäbler \& Maercker, 2011) and an increase (rather than a decrease) of vengeful inclinations (Lillie \& Strelan, 2016).
On the other hand, victims sometimes perceive punishment fantasies to be healing (Goldner et al., 2019), and to help close the "injustice gap" (Haen \& Weber, 2009).

Interestingly, punitive fantasies may also be an element of psychotherapeutic intervention techniques, such as imagery rescripting (ImRs; Holmes et al., 2007). In ImRs, aversive emotional memories that are associated with negative affective states are activated and changed: That is, the person is first instructed to imagine the aversive memory (e.g., sexual harassment) as vividly as possible. Next, the person is guided to modify the aversive memory according to their needs. More specifically, they either imagine changing the situation actively (i.e., active ImRs) or they imagine other people changing the situation for them (i.e., passive ImRs). Importantly, recent meta-analytical evidence shows that ImRs exerts positive effects on psychological symptoms related to aversive emotional memories (Morina et al., 2017).

Although ImRs has mainly been used in the clinical field to deal with rather severe traumatic incidents, ImRs may also help victims of minor injustices to cope with their negative affective state. That is, ImRs may include punitive fantasies in which either victims themselves (active ImRs) or third parties (passive ImRs) take action against the harmdoer. To date, it is unclear whether ImRs in sub-clinical samples that include punishment fantasies alleviate or even 
amplify victims' distress and whether active versus passive ImRs have different outcomes on victims' post-transgression emotional experiences. Previous findings with nonclinical samples suggest that ImRs with versus without vengeful fantasies have similar (positive) emotional consequences (Seebauer et al., 2014) and that active ImRs leads to stronger positive affect than passive ImRs (Siegesleitner et al., 2020). However, the robustness of these effects and - more importantly - the underlying psychological mechanisms, remain to be investigated.

Building upon the pertinent social psychological literature, plausible candidates for these mechanisms are (a) empowerment and (b) justice-related satisfaction. First, fantasizing about the punishment of the harm-doer may increase victims' sense of empowerment (Strelan et al., 2017, 2020), especially if victims engage in punishment themselves (active ImRs). The empowering effects of fantasizing about punishment may, in turn, lead to a decrease in negative and an increase in positive affect (Shnabel \& Nadler, 2008). Second, seeing the harm-doer being punished may increase victims' justice-related satisfaction, which has been defined as a subjective sense of justice served, deservingness, and psychological closure (Funk et al., 2014; Gollwitzer et al., 2011). Thus, both passive and/or active ImRs may decrease negative and increase positive affect via justice-related satisfaction.

Based on these considerations, we hypothesized that ImRs (either active or passive) would more strongly increase positive affect and decrease negative affect compared to two control conditions (i.e., pleasant imagery and imagery rehearsal; see below). Furthermore, we aimed to test the differential effects of active versus passive ImRs on victims' affective states. We predicted that active ImRs would lead to a stronger increase in positive affect and a decrease in negative affect than passive ImRs. Lastly, our experiment enabled us to explore the mechanism(s) underlying an effect of actively punishing the transgressor during ImRs (vs. seeing the transgressor being punished by a third party) on victims' affective state via empowerment and justice-related satisfaction.

\section{Method}

The experiment was preregistered (https://aspredicted. org/zt5gv.pdf). Materials, data, and analyses scripts are available on the Open Science Framework (OSF; https:// osf.io/45362). We report how we determined our sample size, data exclusions, all manipulations, and measures. Ethics approval was granted from a local IRB.

First, participants watched a video clip in which they were depicted as victims of a moderate-level injustice (i.e., being accused of plagiarism because of a student stealing their assignment). Next, they were randomly assigned to one of four conditions: Two ImRs conditions (active and passive) and two control conditions. Subsequently, empowerment, justice-related satisfaction, and positive and negative affect were measured via self-report.

\section{Sample}

We conducted an a priori power analysis using $\mathrm{G}^{*}$ Power (Faul et al., 2009). Specifically, we aimed to detect a small to medium-sized effect of $f=.175$ in a one-factorial analysis of variance (ANOVA) (4 conditions; between-subjects) with a power of $1-\beta=.80$, given $\alpha=.05$. This resulted in a sample size of $N=360$ participants. Due to time constraints, we decided to stop collecting data after May 26, 2020 , if $N>280$ by that time (i.e., enabling us to detect effects of $f=.20$ and bigger; we determined this as the smallest effect size of interest; Rindskopf, 1997).

Only students could participate in the experiment (given that the injustice episode was specifically tuned to a student affair). Participants were recruited through mailing lists and social media. Participants received course credit and had a chance to win gift vouchers in exchange for participation. As preregistered, data collection was stopped on May 27, 2020, after collecting more than 280 participants. Overall, 386 participants started and 296 (71\%) completed the experiment. We excluded cases indicating $(n=4)$ or implying careless responding (i.e., failing any of the attention checks; $n=20)$. In our final sample $(N=272)$, the majority of participants were female $(n=217 ; 80 \%)$. Ages ranged between 18 and 67 years $(M=24.65, S D=7.65)$. Participants were almost evenly distributed across conditions $\left(n_{\text {active ImRs }}=68 ; n_{\text {passive ImRs }}=68 ; n_{\text {pleasant } \text { imagery }}=67\right.$; $n_{\text {imagery rehearsal }}=69$ ).

\section{Measures and Procedure}

After providing informed consent and demographic information, participants were asked to imagine themselves being the victim of a transgression. Following a previously used paradigm (e.g., Holmes \& Bourne, 2008), participants watched a 2-minute video clip filmed from a first-person perspective. The protagonist in this video (participants were asked to picture themselves in this position) was a female student disputing with a male student. In this dispute, the protagonist reported having been unjustly accused of plagiarism in a recent assignment. The other student (the transgressor), who was responsible for the plagiarism, admitted that he denounced the victim to the professor and explicitly said he would not be willing to take this back and confess his deed.

After watching the video, participants reported their affective state (this was included as a control measure that 
is not pertinent for the present manuscript; 10 items, $\Omega \mathrm{t}=.86$; see Revelle \& Zinbarg, 2009), before being randomly assigned to one of the four experimental conditions. In each condition, participants received audio-guided instructions.

This instructed intervention was applied to achieve an experimentally controlled and highly standardized procedure (for a similar approach see, e.g., Kunze et al., 2019).

\section{Treatment Conditions}

In the active ImRs condition, participants were instructed to imagine themselves intervening actively and retaliating directly against the transgressor. Specifically, they imagined having secretly audiotaped the entire dispute with the transgressor, presenting this tape to the professor, requesting the transgressor to be punished, and receiving the grade she deserved for her assignment (which was granted). In the passive ImRs condition, participants were instructed to imagine another person intervening. Specifically, participants imagined the professor entering the room at the end of the dispute, stating that she had listened to the argument coincidentally. From what she had heard, she decided to punish the transgressor and to grant the victim the grade she deserved.

\section{Control Conditions}

In the imagery rehearsal condition, participants listened to a detailed re-telling of the experienced injustice. In the pleasant imagery condition, participants were guided on a dream journey through nature. These control conditions were based on previous research (e.g., Hagenaars \& Arntz, 2012; Tolgou et al., 2018) and promised to control for the effects of imagery (both conditions), the effects of re-activating the memory of the aversive situation (imagery rehearsal), and the effects of positive imagery (pleasant imagery). Consequently, differences between treatment and control conditions can arguably be ascribed to the content of the ImRs conditions (rather than, e.g., the act of imagery itself).

\section{Dependent Measures}

Subsequently, participants answered dependent variables in randomized order. Unless stated otherwise, items were answered on 6-point Likert scales ranging from $1=$ completely disagree to $6=$ completely agree. We assessed participants' empowerment with 14 items. Eleven items were adapted from research that has investigated the empowering effects of punishment and forgiveness (Strelan et al., 2017, 2020). Three items were adopted from a more general self-efficacy scale (Beierlein et al., 2013). Notably, we deviate from the preregistration in that we actually planned to treat empowerment and situational self-efficacy as two separate constructs, despite their obvious natural conceptual overlap (however, see Skinner, 1996). However, given a strong correlation between the two constructs $(r=.83)$ and almost identical results with regard to the hypothesis tests, we decided to merge all items into one measure that we refer to as empowerment throughout the manuscript. The scale showed very good reliability, $\Omega_{\mathrm{t}}=.95$ (see Forbes et al., 2021). We further measured participants' justicerelated satisfaction with 12 items (Funk et al., 2014). Again, the scale showed very good reliability, $\Omega_{\mathrm{t}}=.93$. Participants' positive and negative affect were assessed with the Positive and Negative Affect Schedule (PANAS; Watson et al., 1988) on a 6-point Likert-type scale (from $1=$ not at all to $6=$ extremely). Both the positive and negative affect subscales comprised 10 items each and showed good reliabilities $\left(\Omega_{\mathrm{t}}=.82\right.$ and $\Omega_{\mathrm{t}}=.91$, respectively).

Next, participants answered several control questions (e.g., on the intrusiveness of the interventions; see full material and data in our supplementary material on the OSF; https://osf.io/45362), three simple attention check questions, and one item asking participants directly whether they participated attentively. Participants were thanked and debriefed.

\section{Results}

To test our preregistered hypotheses, we conducted separate ANOVAs with two contrasts (Contrast 1: both ImRs = +1 vs. both control conditions $=-1$; Contrast 2 : active $=$ +1 vs. passive ImRs $=-1$, both control conditions $=0$ ) for each of the dependent variables. Means and distributions of all dependent variables for each condition are depicted in Figure 1. We report our findings for each dependent variable, separately, in the following.

\section{Justice-Related Satisfaction}

Participants in the two treatment conditions (active ImRs: $M=3.22, S D=1.26$; passive ImRs: $M=3.20, S D=1.37$ ) were more satisfied than participants in the two control conditions (pleasant imagery: $M=1.83, S D=0.56$; imagery rehearsal: $M=1.48, S D=0.34$ ), mirrored by a significant effect of Contrast $1, t(269)=12.93, p<.001, d=1.58$. However, the difference in justice-related satisfaction between the two treatment conditions (Contrast 2) was not significant, $t(269)=0.16, p=.874, d=0.02$.

\section{Empowerment}

Participants in the two treatment conditions (active ImRs: $M=4.44, S D=1.17$; passive ImRs: $M=3.25, S D=0.94$ ) felt, 

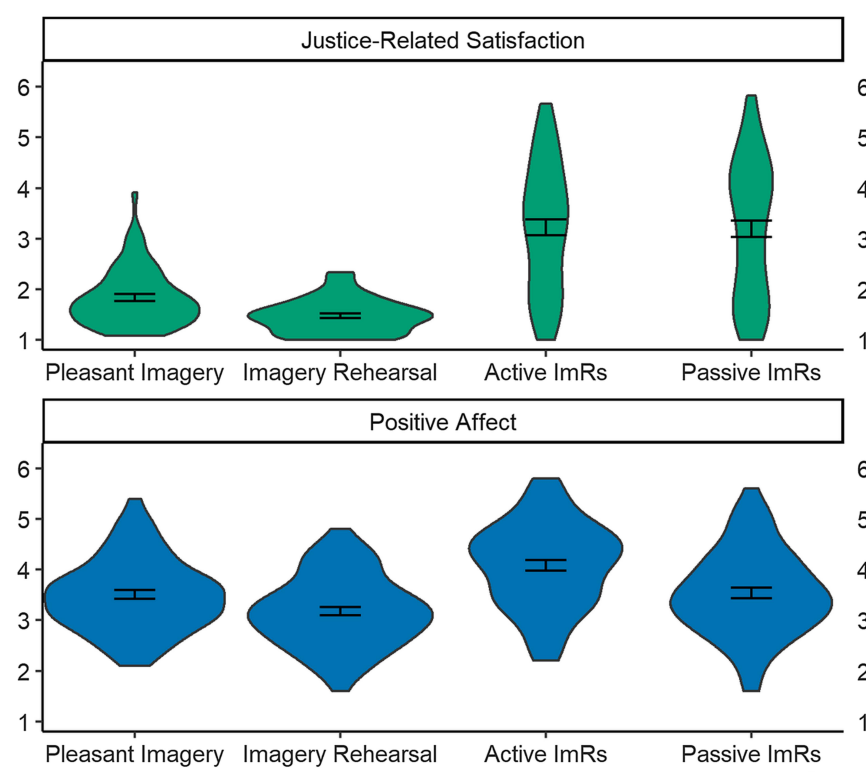
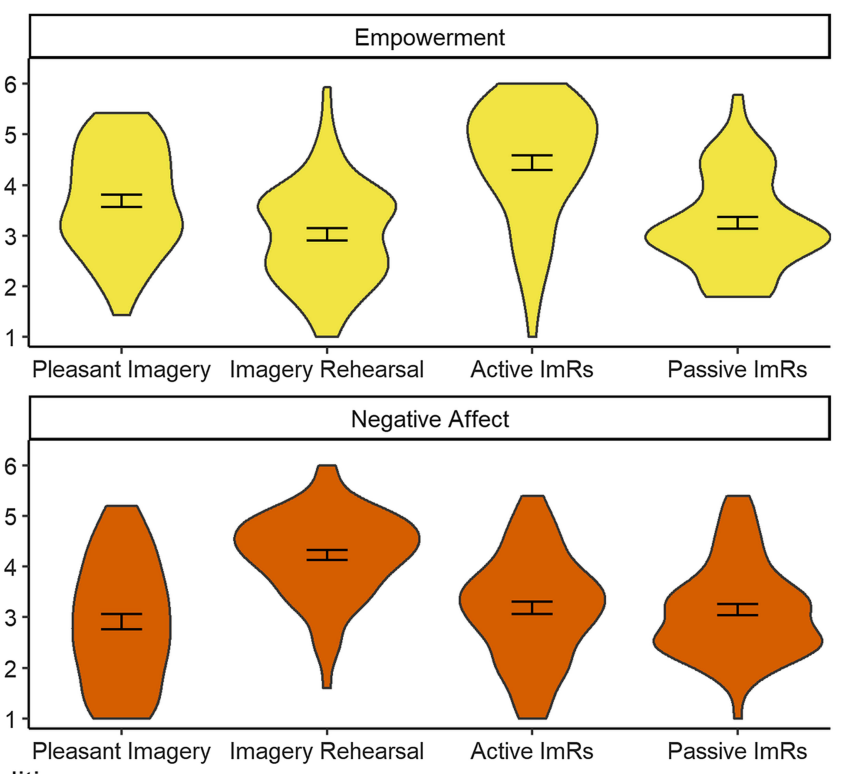

Figure 1. Means and distributions of all dependent variables for each condition. Error bars represent one standard error of the mean.

on average, more empowered than participants in the two control conditions (pleasant imagery: $M=3.69, S D=$ 1.02; imagery rehearsal: $M=3.02, S D=0.99), t(269)=$ 3.86, $p<.001, d=0.47$ (Contrast 1). Note that this effect was, however, largely driven by the superiority of active ImRs over passive ImRs. This is also reflected in a significant effect of Contrast $2, t(269)=6.56, p<.001, d=0.80$.

\section{Positive Affect}

Participants in the two treatment conditions (active ImRs: $M=4.09, S D=0.85$; passive ImRs: $M=3.54, S D=0.84$ ) experienced more positive affect than those in the control conditions (pleasant imagery: $M=3.50, S D=0.71$; imagery rehearsal: $M=3.18, S D=0.70), t(269)=5.00, p<.001$, $d=0.61$ (Contrast 1 ). This, again, was largely driven by the positive effect of active ImRs as compared to passive ImRs, $t(269)=4.08, p<.001, d=0.50$ (Contrast 2).

\section{Negative Affect}

Participants in the treatment conditions (active ImRs: $M=3.18, S D=1.04$; passive ImRs: $M=3.15, S D=0.92$ ) experienced less negative affect than those in the control conditions (pleasant imagery: $M=2.91, S D=1.20$; imagery rehearsal: $M=4.23, S D=0.84), t(269)=-3.08, p=.002$, $d=-0.38$ (Contrast 1 ). Contrary to our hypothesis, there were no differences between active and passive ImRs, $t(269)=0.19, p=.847, d=0.02$ (Contrast 2).

\section{Mediation Analysis}

Conducting a (bootstrapped) mediation model using the lavaan package in $\mathrm{R}$, we tested the effects of the two contrasts on positive and negative affect (as dependent variables) via justice-related satisfaction and empowerment (as mediators; this analysis was not part of our preregistration). As depicted in Figure 2, results corroborate that, for experiencing justice-related satisfaction, it does not matter whether ImRs is active or passive, as long as victims engage in punitive fantasies (which was part of both ImRs). By contrast, to experience empowerment, it is indeed important that victims defend themselves, rather than receiving help from a third party. Importantly, both justice-related satisfaction and empowerment were independently associated with participants' affective states (i.e., negative affect and although to a lesser degree - positive affect).

\section{Discussion}

The experience of injustice commonly leads to negative emotions and may, eventually, facilitate the development of psychological disorders. Based on approaches from clinical psychology, the present research adapted ImRs techniques to deal with "minor" cases of experienced injustice. Specifically, we tested whether ImRs, in which either victims themselves (active ImRs) or third parties (passive ImRs) take action against the harm-doer, help victims to cope with an injustice more effectively than 


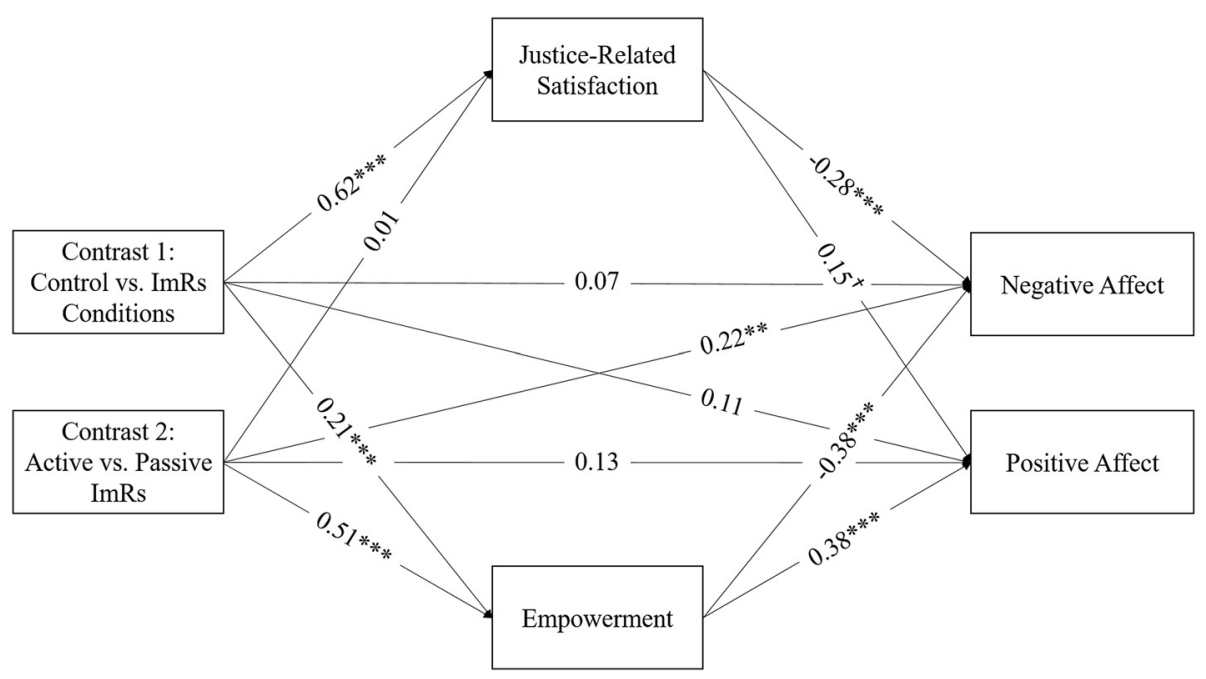

Figure 2. Mediation model on the effects of the imagery treatments on positive and negative affect through justice-related satisfaction and feelings of empowerment. Contrasts are coded as follows. Contrast 1: Both control conditions -1 and both ImRs conditions +1 . Contrast 2: Active ImRs +1 and passive ImRs -1 (control conditions = 0). Path coefficients reflect standardized effects. ${ }^{\dagger} p<.10 ;{ }^{* \star} p<.01 ;{ }^{* \star \star} p<.001$.

pleasant imagery or imagery rehearsal. We further compared the efficacy of active versus passive ImRs and examined the psychological mechanisms underlying the effects of the imagery treatments on individuals' affective states.

Results showed that both active and passive ImRs increased victims' positive affect as compared to the two control conditions (pleasant imagery and imagery rehearsal) and that active ImRs in particular had an effect on positive affect. These results replicate the positive effects of ImRs on people's affective states (Siegesleitner et al., 2019), particularly regarding the effect of active ImRs on positive affect (Siegesleitner et al., 2020).

Interestingly, in the present experiment, victims experienced justice-related satisfaction irrespective of whether they (active ImRs) or someone else (passive ImRs) intervened. Victims' feelings of empowerment, however, were evoked only by actively intervening against the transgressor. This is at odds with recent research (Siegesleitner et al., 2020) showing that active and passive ImRs equally increased individuals' self-efficacy (a construct that is arguably closely related to empowerment). Although speculative, this may be caused by the perspectives participants were asked to take in the injustice. That is, participants imagined being the victims of the injustice in the present research, whereas they were observers in the research by Siegesleitner and colleagues. Future research is needed to test this hypothesis.

Lastly, the present research adds to the literature by showing that the positive effects of ImRs on people's affective states can (partially) be ascribed to victims' feelings of empowerment and justice-related satisfaction as independent mediators. This has particularly interesting implications for more applied settings (e.g., psychological treatment) in that it sheds light on the processes underlying the positive effects of ImRs.

Notably, the approaches applied in the present research were modified versions of "classical" clinical interventions. We, therefore, adapted these treatments to an experimentally controlled, standardized, non-autobiographical setup, which came at the cost of sacrificing ecological validity and which may suffer from method-inherent demand effects of scenario experiments. Importantly, however, participants indicated that they were very well able to put themselves into the offense situation $(M=5.10 ; S D=$ 0.80 ; on a scale from 1 to 6$)$ and the audio-guided treatments $(M=4.86 ; S D=0.89)$ and process the information with a vivid imagination. Nevertheless, it remains to be tested whether the findings from the present experiment can be generalized to clinical applications.

In addition, some limitations of the present research ought to be acknowledged. First, with regard to the psychological mechanisms investigated, we measured (instead of manipulated) the mediators examined herein, thus, prohibiting any strong causal claims. Second, the two ImRs conditions differed from the control conditions in various aspects (e.g., involving a third person, containing a conflict resolution), which makes it difficult to specify exactly which aspects were responsible for the effects we observed here. We designed our control conditions to yield a high degree of comparability between our experiment and previous research on ImRs (e.g., Hagenaars \& Arntz, 2012). Despite these strategic advantages, our choice of control conditions can also be criticized, for instance, for the fact that none of them included a non-punitive, constructive conflict 
resolution strategy between the victim and the transgressor. Relatedly, the ImRs conditions may have been perceived as more realistic than the control conditions. Indeed, participants rated ("The situation seemed very realistic to me.") the pleasant rehearsal as less realistic $(M=4.01, S D=$ 1.39) than the imagery rehearsal $(M=4.46, S D=1.32)$, the active ImRs $(M=4.47, S D=1.24)$, and the passive ImRs $(M=4.35, S D=1.28)$. However, differences were rather small (all $d<0.28$ ). Finally, the present research cannot answer whether ImRs involving punitive fantasies has negative effects (e.g., aggression); however, past research indicates that such fantasies do not increase aggression (Seebauer et al., 2014).

With these caveats in mind, we still argue that the present research replicates and adds to the literature on ImRs and offers insights into how clinical interventions may be applied to social psychological phenomena. Specifically, we provide evidence that ImRs can also be a promising technique to deal with "minor" cases of experienced injustice, such as being deceived and falsely accused of a transgression. Thus, this project can serve as a blueprint for future research on the border of clinical and social psychological research.

\section{References}

Barber, L., Maltby, J., \& Macaskill, A. (2005). Angry memories and thoughts of revenge: The relationship between forgiveness and anger rumination. Personality and Individual Differences, 39(2), 253-262. https://doi.org/10.1016/j.paid.2005.01.006

Beierlein, C., Kemper, C. J., Kovaleva, A., \& Rammstedt, B. (2013). Short scale for measuring general self-efficacy beliefs (ASKU). Methoden, Daten, Analysen, 7(2), 251-278. https://doi.org/ 10.12758/mda.2013.014

Eadeh, F. R., Peak, S. A., \& Lambert, A. J. (2017). The bittersweet taste of revenge: On the negative and positive consequences of retaliation. Journal of Experimental Social Psychology, 68, 27-39. https://doi.org/10.1016/j.jesp.2016.04.007

Faul, F., Erdfelder, E., Buchner, A., \& Lang, A.-G. (2009). Statistical power analyses using G*Power 3.1: Tests for correlation and regression analyses. Behavior Research Methods, 41(4), 1149-1160. https://doi.org/10.3758/BRM.41.4.1149

Forbes, M. K., Greene, A. L., Levin-Aspenson, H. F., Watts, A. L., Hallquist, M., Lahey, B. B., Markon, K. E., Patrick, C. J., Tackett, J. L., Waldman, I. D., Wright, A. G. C., Caspi, A., Ivanova, M., Kotov, R., Samuel, D. B., Eaton, N. R., \& Krueger, R. F. (2021). Three recommendations based on a comparison of the reliability and validity of the predominant models used in research on the empirical structure of psychopathology. Journal of Abnormal Psychology, 130(3), 297-317. https://doi.org/ 10.1037/abn0000533

Funk, F., McGeer, V., \& Gollwitzer, M. (2014). Get the message: Punishment is satisfying if the transgressor responds to its communicative intent. Personality \& Social Psychology Bulletin, 40(8), 986-997. https://doi.org/10.1177/0146167214533130

Gäbler, I., \& Maercker, A. (2011). Revenge phenomena and posttraumatic stress disorder in former East German political prisoners. Journal of Nervous and Mental Disease, 199(5), 287-294. https://doi.org/10.1097/NMD.0b013e3182174fe7
Goldner, L., Lev-Wiesel, R., \& Simon, G. (2019). Revenge fantasies after experiencing traumatic events: Sex differences. Frontiers in Psychology, 10, Article 886. https://doi.org/10.3389/ fpsyg.2019.00886

Gollwitzer, M., Meder, M., \& Schmitt, M. (2011). What gives victims satisfaction when they seek revenge? European Journal of Social Psychology, 41(3), 364-374. https://doi.org/10.1002/ ejsp.782

Haen, C., \& Weber, A. M. (2009). Beyond retribution: Working through revenge fantasies with traumatized young people. Arts in Psychotherapy, 36(2), 84-93. https://doi.org/10.1016/j. aip.2009.01.005

Hagenaars, M. A., \& Arntz, A. (2012). Reduced intrusion development after post-trauma imagery rescripting; An experimental study. Journal of Behavior Therapy and Experimental Psychiatry, 43(2), 808-814. https://doi.org/10.1016/j.jbtep.2011.09.005

Hofmann, W., Brandt, M. J., Wisneski, D. C., Rockenbach, B., \& Skitka, L. J. (2018). Moral punishment in everyday life. Personality and Social Psychology Bulletin, 44(12), 1697-1711. https:// doi.org/10.1177/0146167218775075

Holmes, E. A., Arntz, A., \& Smucker, M. R. (2007). Imagery rescripting in cognitive behaviour therapy: Images, treatment techniques and outcomes. Journal of Behavior Therapy and Experimental Psychiatry, 38(4), 297-305. https://doi.org/ 10.1016/j.jbtep.2007.10.007

Holmes, E. A., \& Bourne, C. (2008). Inducing and modulating intrusive emotional memories: A review of the trauma film paradigm. Acta Psychologica, 127(3), 553-566. https://doi.org/ 10.1016/j.actpsy.2007.11.002

Kunze, A. E., Arntz, A., \& Kindt, M. (2019). Investigating the effects of imagery rescripting on emotional memory: A series of analogue studies. Journal of Experimental Psychopathology, 10(2), Article 204380871985073. https://doi.org/10.1177/ 2043808719850733

Lillie, M., \& Strelan, P. (2016). Careful what you wish for: Fantasizing about revenge increases justice dissatisfaction in the chronically powerless. Personality and Individual Differences, 94, 290-294. https://doi.org/10.1016/j.paid.2016. 01.048

Morina, N., Lancee, J., \& Arntz, A. (2017). Imagery rescripting as a clinical intervention for aversive memories: A meta-analysis. Journal of Behavior Therapy and Experimental Psychiatry, 55, 6-15. https://doi.org/10.1016/j.jbtep.2016.11.003

Pedersen, W. C., Denson, T. F., Goss, R. J., Vasquez, E. A., Kelley, N. J., \& Miller, N. (2011). The impact of rumination on aggressive thoughts, feelings, arousal, and behaviour. British Journal of Social Psychology, 50(2), 281-301. https://doi.org/ $10.1348 / 014466610 \times 515696$

Revelle, W., \& Zinbarg, R. (2009). Coefficients alpha, beta, omega, and the glb: Comments on Sijtsma. Psychometrika, 74(1), 145154. https://doi.org/10.1007/s11336-008-9102-z

Rindskopf, D. M. (1997). Testing "small", not null, hypotheses: Classical and Bayesian approaches. In L. L. Harlow, S. A. Mulaik, \& J. H. Steiger (Eds.), What if there were no significance tests? (pp. 319-332). Psychology Press.

Seebauer, L., Froß, S., Dubaschny, L., Schönberger, M., \& Jacob, G. A. (2014). Is it dangerous to fantasize revenge in imagery exercises? An experimental study. Journal of Behavior Therapy and Experimental Psychiatry, 45(1), 20-25. https://doi.org/ 10.1016/j.jbtep.2013.07.003

Shnabel, N., \& Nadler, A. (2008). A needs-based model of reconciliation: Satisfying the differential emotional needs of victim and perpetrator as a key to promoting reconciliation. Journal of Personality and Social Psychology, 94(1), 116-132. https://doi.org/10.1037/0022-3514.94.1.116

Siegesleitner, M., Strohm, M., Wittekind, C. E., Ehring, T., \& Kunze, A. E. (2019). Effects of imagery rescripting on consolidated 
memories of an aversive film. Journal of Behavior Therapy and Experimental Psychiatry, 62, 22-29. https://doi.org/10.1016/j. jbtep.2018.08.007

Siegesleitner, M., Strohm, M., Wittekind, C. E., Ehring, T., \& Kunze, A. E. (2020). Improving imagery rescripting treatments: Comparing an active versus passive approach. Journal of Behavior Therapy and Experimental Psychiatry, 69, Article 101578. https://doi.org/10.1016/j.jbtep.2020.101578

Skinner, E. A. (1996). A guide to constructs of control. Journal of Personality and Social Psychology, 71(3), 549-570. https://doi. org/10.1037/0022-3514.71.3.549

Strelan, P., Di Fiore, C., \& Van Prooijen, J. W. (2017). The empowering effect of punishment on forgiveness. European Journal of Social Psychology, 47(4), 472-487. https://doi.org/ 10.1002/ejsp.2254

Strelan, P., Van Prooijen, J. W., \& Gollwitzer, M. (2020). When transgressors intend to cause harm: The empowering effects of revenge and forgiveness on victim well-being. British Journal of Social Psychology, 59(2), 447-469. https://doi.org/10.1111/ bjso.12357

Tolgou, T., Rohrmann, S., Stockhausen, C., Krampen, D., Warnecke, I., \& Reiss, N. (2018). Physiological and psychological effects of imagery techniques on health anxiety. Psychophysiology, 55(2). https://doi.org/10.1111/psyp.12984

Watson, D., Clark, L. A., \& Tellegen, A. (1988). Development and validation of brief measures of positive and negative affect: The PANAS scales. Journal of Personality and Social Psychology, 54(6), 1063-1070. https://doi.org/10.1037/0022-3514.54.6.1063

\section{History}

Received July 1, 2020

Revision received December 4, 2020

Accepted December 23, 2020

Published online September 9, 2021

\section{Publication Ethics}

Ethics approval was granted from a local IRB.

\section{Open Data}

The experiment was preregistered (https://aspredicted.org/zt5gv. pdf). Materials, data, and analyses scripts are available on the Open Science Framework (OSF; https://osf.io/45362). We report how we determined our sample size, data exclusions, all manipulations, and measures.

\section{Mathias Twardawski}

Social Psychology

Department of Psychology

Ludwig-Maximilians-Universität München

Leopoldstr. 13

80802 Munich

Germany

m.twardawski@lmu.de 